\title{
Educação, classe, gênero e voto no Brasil imperial: Lei Saraiva - $1881^{1}$
}

\section{Education, class, gender and the vote in imperial Brazil: the Saraiva Law - 1881}

\author{
Alceu Ravanello Ferraro ${ }^{2}$
}

\begin{abstract}
RESUMO
Este trabalho trata da reforma eleitoral de introdução do voto direto no Brasil, conhecida como Lei Saraiva (1881), quase no final do Império. Focaliza duas questões que se entrecruzam: a de como os liberais brasileiros se posicionaram acerca do acesso da classe trabalhadora, dos analfabetos e das mulheres ao voto; e aquela do uso que os parlamentares liberais brasileiros fizeram das ideias do liberal inglês John Stuart Mill no encaminhamento da mencionada reforma. Na perspectiva teórico-metodológica da História Social ou da Sociologia Histórica e tendo como base os debates travados na Câmara dos Deputados, como registrados nos Anais (1879-1880), e textos filosófico-políticos do referido liberal inglês, este estudo mostra como os parlamentares brasileiros: a) radicalizaram o critério econômico de Stuart Mill, endurecendo os mecanismos de comprovação da renda mínima (censo) para votar; b) incorporaram na nova Lei o critério milliano de exclusão dos analfabetos do direito de voto, num país com mais de $80 \%$ de analfabetos, carente de escolas e sem obrigatoriedade escolar ainda; e c) ignoraram a proposta do autor inglês de extensão do direito de voto às mulheres. Mostra ainda que o resultado da reforma foi um enorme retrocesso em termos de participação política popular, sem o prometido avanço na escolarização.
\end{abstract}

Palavras-chave: educação; classe; gênero; voto; Império.

1 Trabalho produzido dentro de projeto de pesquisa apoiado pelo Conselho Nacional de Desenvolvimento Científico e Tecnológico (CNPq).

2 Universidade Federal do Rio Grande do Sul (UFRGS). Porto Alegre, Rio Grande do Sul, Brasil. Avenida Paulo Gama, 110 - Farroupilha. CEP: 90040-060. 


\begin{abstract}
The paper discusses the electoral reform almost at the end of the Empire that introduced the direct vote in Brazil, known as the Saraiva Law (1881). It focuses on two issues that are interwoven: the position taken by Brazilian liberals regarding access for the working class, illiterates, and women to the vote, and the use of the liberal ideas of John Stuart Mill, the English Liberal, by the Brazilian liberal politicians in conducting the aforementioned reform. From the theoretical-methodological perspective of Social History or Historical Sociology, and based on the debates held in the Chamber of Deputies, as recorded in the Anais (Proceedings) (1879-1880), and philosophical-political texts of the aforementioned English liberal, the study shows how Brazilian deputies: a) radicalized the economic criterion of Stuart Mill, creating harsher mechanisms to prove minimum income (census) to vote; b) incorporated the Millian criterion of exclusion of illiterates from the right to vote into the new Law, in a country with more than $80 \%$ illiterates, lacking schools, and without mandatory schooling at that time; and c) ignored the proposal by the English author of extending the right to vote to the women. It also shows that the result of the reform was a huge step backwards, in terms of popular political participation, without the promised advance in schooling.
\end{abstract}

Keywords: education; class; gender; vote; Empire.

\title{
Objetivo e método
}

O Decreto $n^{\circ} 3.029$, de 9 de janeiro de 1881, conhecida como Lei Saraiva, atendendo a uma demanda inscrita na bandeira do Partido Liberal, introduziu o voto direto no Império do Brasil, mas a um preço extremamente elevado, tanto no que se refere à participação popular no processo político quanto no que concerne ao prometido acesso à escola.

O texto aborda duas questões que se entrecruzam: a de como os liberais brasileiros se posicionaram acerca da participação da classe trabalhadora, dos analfabetos e da mulher no processo eleitoral e aquela do uso que os parlamentares liberais brasileiros fizeram das ideias ou teses do liberal inglês John Stuart Mill no encaminhamento da referida reforma eleitoral. Tudo isto, a meio caminho entre o início da crise do Império (1868) e a República (1889). Na realidade, um conjunto de crises: a religiosa, a militar, a escravista e a eleitoral. O período em questão vai de dezembro de 1878, quando o Imperador chama os liberais para a tarefa de introduzir o voto direto ou em turno único, à publicação da Lei Saraiva em janeiro de 1881. 
O interesse pelo estudo dessa reforma eleitoral, tendo como base os anais da Câmara e do Senado, foi despertado principalmente pela leitura dos capítulos "Liberais contra Liberais" e "A Lei Saraiva", no volume 5 de $O$ Brasil Monárquico de Sérgio Buarque de Holanda (1977, p. 195-255). Ali se tem, por exemplo, esta análise sugestiva a respeito do pensamento de José Bonifácio, o Moço, sobre o voto dos analfabetos:

Como the representassem que o voto menos esclarecido de grandes massas de iletrados punha em risco até as instituições do país, devido a formarem a grande maioria da população do império, retrucou o orador que, por essa forma, se invertiam os dados do problema. Se formam a grande maioria da população os analfabetos, não deveria ser esse exatamente um motivo para não excluí-los? (HOLANDA, 1977, p. 216).

A informação obtida da Biblioteca Nacional de que os Anais relativos ao período em questão estavam disponíveis na internet permitiram iniciar a pesquisa ainda no início de 2007, trabalho que perdura até hoje, sempre dentro de projetos apoiados pelo Conselho Nacional de Desenvolvimento Científico e Tecnológico (CNPq): o primeiro - "Gênero raça e escolarização no Brasil: traçando a trajetória da relação" -, desenvolvido no período 2007-2010; o segundo, "Da construção do analfabetismo como problema nacional (1878-1881), aos desafios ainda postos à escolarização e alfabetização no Brasil (1990-2010)", em desenvolvimento no período 2010-2015.

Do ponto de vista metodológico, o estudo aqui desenvolvido insere-se no que P. Burke (1980, p. 26) define como sociologia histórica ou história social. As fontes básicas utilizadas são duas: os Anais da Câmara dos Deputados,

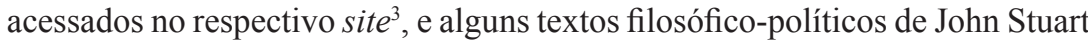
Mill, particularmente: Sobre a Liberdade (1991), de 1859; Considerações Sobre o Governo Representativo (1981), de 1861; El utilitarismo (1997), de 1861, e The subjection of Women, de 1869. Esses quatro textos foram reunidos na coletânea On Liberty and Others Essays (MILL, 2008), obra que serviu também para conferência das traduções utilizadas.

O presente texto considerou apenas os debates havidos na Câmara dos Deputados, onde as referências a Stuart Mill foram muito mais frequentes. A pesquisa, porém, compreendeu a exploração, a localização e a leitura do material

3 Site da Câmara dos Deputados, disponível em: $<$ http://imagem.camara.gov.br/pesquisa diario_basica.asp>. 
de interesse, sessão por sessão, nos Anais tanto da Câmara quanto do Senado, em todo o período de dezembro de 1878 a janeiro de 1881, do que resultaram cerca de 3.000 folhas impressas, que já serviram de base para algumas publicações focando diferentes aspectos dentro da temática da pesquisa: A negação do direito devoto aos analfabetos na lei Saraiva (1881): uma exclusão de classe? (FERRARO, 2008); A construção social do analfabetismo como questão nacional: 1878-1881 (FERRARO, 2009); Dos argumentos invocados pelos liberais para a exclusão dos analfabetos do direito de voto (FERRARO; LEÃO, 2012); e $A$ participação de Rui Barbosa na reforma eleitoral que excluiu os analfabetos do direito de voto no Brasil (LEÃO, 2013).

Talvez em poucos outros momentos da história do país a Câmara dos Deputados tenha reunido intelectuais e tribunos de tanta expressão como a legislatura que encaminhou a reforma eleitoral. Baste lembrar José Bonifácio, o Moço, Joaquim Nabuco, Saldanha Marinho e Silveira Martins, todos da pequena oposição liberal, e Rui Barbosa, pelo lado da maioria liberal que apoiava o governo.

Mas há duas questões preliminares a esclarecer: o contexto em que se deu a reforma eleitoral e a presença do pensamento de Stuart Mill no encaminhamento desta.

\section{8: o contexto e a tarefa atribuída aos liberais}

Em 15 de dezembro de 1878, o Imperador Pedro II chamou um liberal de confiança, o Visconde de Sinimbu (João Lins Vieira Cansanção de Sinimbu), determinando-lhe que constituísse um ministério liberal para a tarefa específica e exclusiva de introdução da eleição direta no Império. A Fala do Trono foi curta e incisiva:

Reconhecida a necessidade de substituir o sistema eleitoral vigente pelo de eleição direta, cumpre que decreteis mediante reforma constitucional, afim de que o concurso de cidadãos, devidamente habilitados a exercer tão importante direito, contribua eficazmente para realidade do sistema representativo (FALA DO TRONO, 1878, p. 92).

A convocação dos liberais se deu em meio à chamada crise eleitoral, que, somada às crises militar, religiosa e escravista, iria concorrer na pavimentação 
do caminho que, numa década, levaria à República. O pensamento liberal vinha marcando presença incômoda, no Brasil imperial, desde o período da Independência e da Constituição de 1824. Por mais que as ideias liberais se fossem difundindo e tomando corpo, fenômeno que Romero (1979, p. 163) chamaria "bando de ideias novas" a esvoaçar sobre as cabeças, vindo de todos os pontos do horizonte, o Imperador não escondia sua preferência pelos conservadores. Historiadores conceituados têm o ano de 1868 como marco divisório dentro do Segundo Reinado, apontando já na direção da República (HOLANDA, 1977, p. 7, por exemplo). Iglesias (HOLANDA, 1982, p. 199), por sua vez, vê o conservador Itaboraí como "o último grande chefe de tipo antigo", representando simplesmente "a grande presença do passado". No fundo, "um ministério conservador quando a Câmara dos Deputados era de maioria progressista, agora liberal". O gabinete Itaboraí, que pusera fim a três breves ministérios liberais (1865/68), tinha sua legitimidade contestada sob o qualificativo de "segundo estelionato eleitoral"; o primeiro se dera em 1848. O referido segundo estelionato eleitoral perdurara por dez anos, até a chamada dos liberais para a tarefa de introdução do voto direto, certamente por influência, entre outros, e talvez principalmente, do pensamento político de John Stuart Mill. Com efeito, o autor inglês rejeitava a eleição em dois turnos, por entender que ela se embasava na suposição infundada de que os poucos eleitores de segundo turno estariam "menos sujeitos do que o Demos [Povo] aos vendavais da paixão popular" (MILL, 2008, p. 346) e superariam, em termos de intelecto e caráter, o nível comum dos seus constituintes ou eleitores de primeiro turno.

No Brasil, ocuparam-se da reforma eleitoral dois ministérios liberais. O primeiro, do Visconde de Sinimbu, já sofrera duros golpes três dias antes da apresentação do projeto na Câmara em 13 de fevereiro de 1879. Como o próprio Sinimbu (1879a, p. 415) esclarece, a divergência que de algum tempo existia no seio do ministério, relacionada à elegibilidade dos acatólicos, gerara uma crise que resultara no afastamento de dois ministros: Silveira Martins e o Barão de Vila Bela. Em relação a isto, em capítulo intitulado "Liberais contra liberais", Holanda (1977, p. 195) descreve de forma precisa a natureza da referida cisão: “[...] abre-se naquela 'câmara unânime', unanimemente liberal, uma dissidência mais profunda, e encabeça-a justamente o irmão de Martim Francisco [de Andrada e Silva]", José Bonifácio (de Andrada e Silva), o Moço. Forma-se, a partir desse dia, a pequena, mas aguerrida oposição liberal que iria infernizar a curta vida do governo Sinimbu.

O projeto Sinimbu, além da elevação do censo de duzentos para um mínimo de quatrocentos mil réis, queria introduzir como condição para votar a capacidade de ler e escrever, ou seja, queria a exclusão dos analfabetos do direito de voto. Aprovado na Câmara, em terceira e última votação, em 9 de junho de 
1879, com 81 votos a favor e apenas 16 contra, o Projeto Sinimbu de reforma eleitoral via reforma da Constituição acaba naufragando no Senado, na sessão de 12 de novembro de 1879, conforme previra o deputado Afonso Celso (1879, p. 112), arrastando consigo o próprio Ministério Sinimbu.

O ministério que o sucede, presidido pelo Conselheiro José Antônio Saraiva (1880a, p. 8-9), assume em 28 de março de 1980, apresentando, no dia seguinte, novo projeto de reforma eleitoral, desta vez, não para atender a um "cumpre que decreteis", mas para realizar a reforma pelo modo que lhe parecesse preferível. Saraiva, homem de grande prestígio no Partido Liberal, tem mais habilidade no encaminhamento do projeto, obtendo, em poucos meses, sua aprovação em ambas as casas legislativas e sua transformação na Lei de 9 de janeiro de 1881, que leva o seu nome.

\section{Por que Stuart Mill?}

O interesse por Stuart Mill deve-se à presença repetida e à influência decisiva de algumas de suas ideias filosófico-políticas no processo de introdução do voto direto no Brasil.

Nascido 1806 (Londres), Stuart Mill falecera em 1873 (Avinhão), apenas seis anos antes do início dos debates sobre a reforma eleitoral no Brasil. Conceituado economista como seu pai, James Mill, é tido por B. Groult (2010, p. 97) - que lhe dá um lugar de destaque em sua obra Le féminisme au masculin (O feminismo no masculino) - simplesmente como "o pensador liberal mais influente do século XIX". Mas ele entra neste estudo principalmente pelos textos filosófico-políticos já referidos. A sua experiência parlamentar, mesmo que breve (1865-1868), ajudou a tornar seu nome conhecido. Por hora, baste dizer que o deputado Rui Barbosa (1880), em discurso proferido na Câmara, pronunciou nada menos do que oito vezes o nome de Stuart Mill, afirmando que via nele uma autoridade das maiores, um grande pensador, cujo liberalismo ia até o radicalismo, e que, entretanto, ele excluía do voto não só os analfabetos, mas também os que ignorassem as primeiras regras do cálculo. O mais interessante é que a autoridade de Stuart Mill tenha sido invocada principalmente contra a posição de alguns senadores que defendiam o voto dos analfabetos. Note-se: o Senado, lembrado com frequência pela alcunha de Sibéria, era visto com reservas pela Câmara liberal.

Mill (1981, p. 5-6) sustenta que o governo não é nem mera arte política nem simples ramo da história natural. Diz ainda que as instituições políticas são 
obra dos homens (work of men), devendo sua origem e existência à vontade humana (MILL, 2008, p. 2074). Assim, feito por homens, esse mecanismo político precisa ser manejado por homens, até por homens comuns, necessitando tanto da participação ativa da população quanto ajustar-se às capacidades e qualidades desses homens assim como eles são (MILL, 2008, p. 207-208).

Segundo o autor, numa democracia há que evitar dois tipos de perigo: "o perigo de um baixo nível de inteligência no corpo representativo e na opinião pública que o controla" (MILL, 1981, p. 71), onde já está implícita a exclusão dos analfabetos do direito de voto; e "o perigo de uma legislação de classes por parte da maioria numérica, sendo ela composta de uma única classe” (p. 71), o que dá suporte ao critério econômico para admissão ao voto. Ele teme a ditadura da maioria constituída por uma única classe social, não sendo difícil imaginar a que classe o autor estava se referindo!

Chega-se, com isto, a um ponto nevrálgico - e contraditório - na obra de Mill: no capítulo VIII de Considerações... (1981) o autor trata da extensão do sufrágio num governo representativo constituído mediante eleição direta. Ali, de um lado, o autor diz que limitar o sufrágio não é solução para o perigo do absolutismo da maioria, porque tal limitação "acarretaria uma exclusão compulsória de uma parte da população de seu direito à representação" (MILL, 1981, p. 87), e, de outro, defende duas exclusões e propõe uma inclusão, que interessam sobremaneira no presente estudo e que serão discutidas a seguir.

\section{As três teses de Stuart Mill}

São três as teses de Stuart Mill que aqui interessam: 1. que só devem votar aqueles que pagam impostos; 2 . que só devem votar aqueles que sabem ler, escrever e executar as operações comuns da aritmética, ficando, assim, excluídos de tal direito ou privilégio ${ }^{5}$ os analfabetos, mas devendo o Estado assegurar educação (escolarização) universal; e 3. que as mulheres também devem ter o direito de voto. Estas teses, claramente formuladas no já referido ensaio sobre

4 Toma-se aqui como fonte o texto inglês, devido a um erro, provavelmente gráfico, na versão brasileira. Com efeito, onde se lê: " [...] que as instituições políticas [...] são obra dos homens, e que eles devem sua origem [...]" (MILL, 1981, p. 6, grifo meu), dever-se-ia dizer: "[...] que as instituições políticas [...] são obra dos homens, e que elas devem sua origem [...]" (MILL, 2008, p. 207, grifo meu).

5 Stuart Mill utiliza ambos os termos - "privilégio" e "direito". Parece que privilégio era o termo mais comumente utilizado na Inglaterra até aproximadamente a década de 1860. 
o governo representativo (MILL, 1981, p. 1-184; MILL, 2008, p. 203-467), eram do conhecimento dos liberais brasileiros do tempo da reforma eleitoral.

A primeira exclusão obedece a um critério econômico, que para Stuart Mill é não pagar imposto: "É importante, também, que a assembleia que vota os impostos, tanto gerais quanto locais, deve ser eleita exclusivamente pelos que pagam os referidos impostos" (MILL, 1981, p. 90). A justificativa é a seguinte: "Os que não pagam impostos, dispondo através de seus votos do dinheiro de outras pessoas, têm todas as razões imagináveis para serem pródigos, e nenhuma para economizar" (p. 90). Para o autor, dar voto aos que não pagam impostos constitui "uma violação do princípio fundamental do governo livre" e equivale a permitir que "estas pessoas ponham suas mãos no bolso alheio" (p. 90).

Esta exclusão de caráter econômico vigorava, no Brasil, desde a Constituição de 1824, através do assim chamado censo, que o deputado Rui Barbosa (1880, p. 355) denomina censo pecuniário, para significar o mecanismo de comprovação de determinado nível renda para poder votar, contrapondo-lhe o termo censo literário para a condição de saber ler e escrever.

A segunda exclusão defendida por Stuart Mill compreende todos os que não saibam ler, escrever e executar as operações comuns da aritmética (os analfabetos):

Encaro como totalmente inadmissível que possa participar do sufrágio uma pessoa que não saiba ler, escrever ou, ainda, executar as operações comuns da aritmética. A justiça exige que, mesmo que o sufrágio não dependa disso, os meios de atingir estes conhecimentos elementares sejam colocados ao alcance de todas as pessoas, seja gratuitamente, seja a um preço que possa ser pago até mesmo pelos mais pobres. [...] O fato de a sociedade não ter cumprido seu dever de tornar este grau de instrução acessível a todos é realmente uma injustiça, mas uma injustiça à qual nos devemos resignar. Se a sociedade houver negligenciado o cumprimento de duas obrigações solenes, a mais importante e mais fundamental deve ser cumprida primeiro: a educação universal deve preceder o sufrágio universal (MILL, 1981, p. 89-90, grifo meu).

Em síntese, para Stuart Mill, analfabeto não vota, mesmo que a sociedade não tenha cumprido com sua obrigação de dar escola; ele é simplesmente um incapaz. Para o autor, o sufrágio universal deve ser precedido pela educação ou escolarização universal. Importante: Mill, ao mesmo tempo em que defende a exclusão dos analfabetos do direito de voto, propõe e defende educação ou escolarização universal como caminho para o voto universal. Mas, note-se, o 
autor tomava como base de seu raciocínio a Inglaterra, já em processo bastante avançado de generalização da instrução.

A inclusão pretendida por Stuart Mill refere-se à extensão do direito de voto às mulheres. No texto Sobre a Liberdade, de 1859, referindo-se ao "quase despótico poder dos maridos sobre as mulheres", Mill argumentara que, para a completa remoção desse mal, nada era mais necessário do que as mulheres gozarem dos mesmos direitos e receberem a mesma proteção da lei, como todas as outras pessoas (MILL, 1991, p. 148). Dois anos mais tarde, em Considerações..., o autor desenvolve seu pensamento a respeito da participação política da mulher. Começa dizendo que, na argumentação anterior, não dera nenhuma atenção à diferença dos sexos, por considerar o problema "tão inteiramente irrelevante, quanto a diferença de altura ou de cor de cabelo" (MILL, 1981, p. 97). Para ele:

Todos os seres humanos têm o mesmo interesse em ter um bom governo; o bem-estar de todos é igualmente afetado por ele, e todos têm direito a uma voz para garantir sua porção de benefícios. Se existir tal diferença, as mulheres necessitam dele mais que os homens, uma vez que, sendo fisicamente mais frágeis, dependem mais das leis e da sociedade para a sua proteção. A humanidade já há muito tempo abandonou os únicos princípios que podem apoiar a conclusão de que as mulheres não devem votar. Hoje em dia, ninguém mais sustenta que as mulheres devam ser escravizadas; que não possam ter nenhum outro pensamento, desejo ou ocupação, que não o de ser burro de carga de seus maridos, seus pais ou seus irmãos (MILL, 1981, p. 97).

Para Stuart Mill, se as mulheres solteiras, e por pouco também as casadas, podem ter fortuna própria e interesses pecuniários e comerciais da mesma maneira que os homens, e se é considerado desejável e conveniente que pensem, escrevam e ensinem, "a incapacidade política [delas] já não mais se baseia em qualquer princípio” (MILL, 1981, p. 97).

O texto citado deixa entrever a perspectiva liberal utilitarista de Stuart Mill, radicada no utilitarismo de Geremy Bentham (MILL, 1997), perspectiva esta, aliás, enfatizada e desenvolvida por Andréa Nye (1995, p. 27-37). Otimista, Mill conclui o capítulo sobre a extensão do voto com uma profecia que não se iria realizar tão cedo como ele imaginava:

antes do transcurso de mais uma geração, a casualidade de sexo [the accident of sex], assim como a casualidade de cor da pele [the accident 
of skin], não será mais considerada uma justificativa suficiente para privar o seu possuidor de igual proteção e dos justos privilégios de um cidadão (MILL, 2008, p. 345).

Vai na mesma direção o texto The Subjection of Women (A Sujeição das Mulheres), de 1869 (MILL, 2008, p. 469-592), que contou com a parceria de sua esposa Harriet Taylor Mill, publicado após a morte desta. Nele o autor sustenta pontos importantes no que se refere aos direitos das mulheres, entre os quais:

Que o princípio que regula as relações sociais existentes entre os sexos - a subordinação legal de um sexo ao outro - é falso em si mesmo, e é hoje um dos maiores obstáculos ao progresso humano; e que ele precisa ser substituído pelo princípio da perfeita igualdade, não se admitindo nenhum poder ou privilégio de um lado, e nenhuma inaptidão do outro (MILL, 2008, p. 471).

E. Badinter (1991, p. 33) diz que, em 1789, a mulher era uma "pessoa inferior, como o é ainda o pobre, o doméstico ou o negro" e que ela seria contada entre os "cidadãos passivos", conforme a célebre distinção do abade Sieyès. Stuart Mill figura como o último da reduzida lista de homens (Poullain de la Barre, Condorcet, Fourier e Stuart Mill) que, na opinião de Groult (2010, p. 14), mereceriam figurar no pouco povoado Panteão dos precursores do feminismo. Não foi, portanto, o primeiro. Quase um século antes dele, Condorcet publicara o texto Sobre a admissão das mulheres ao direito de cidadania (apud BADINTER, 1991, p. 43-57), o "primeiro manifesto feminista da Revolução", nas palavras de Groult (2010, p. 54).

Exposto o pensamento de Stuart Mill, resta investigar como os parlamentares liberais brasileiros se posicionaram em relação a essas três teses do autor e que uso fizeram delas.

\section{Os liberais brasileiros face às exclusões defendidas por Stuart Mill}

Com poucas exceções, os liberais brasileiros aceitavam de muito bom grado os dois critérios de exclusão do direito de voto defendidos pelo autor inglês: o censo, correspondendo ao pagamento de impostos defendido por 
Stuart Mill, e saber ler e escrever. Critérios estes intimamente relacionados, seja a favor seja contra o projeto. Em defesa das referidas exclusões, Florêncio Abreu (1879, p. 319, grifos do autor) sustenta que "[...] entregar o direito de voto, cuja responsabilidade é tão grande, à ignorância e ao pauperismo é que seria criar a mais desgraçada das democracias". Entendia o deputado que a lei que viesse a ser decretada, se quisesse consultar as verdadeiras conveniências públicas, teria que "considerar que na instrução e em uma certa abastança estão em regra representadas a capacidade e a independência precisas para a escolha dos representantes do país. (Apoiados)" (p. 319). Contra o projeto, Gavião Peixoto $(1879$, p. 710) defende o que considera "o justo meio": "quanto à renda, o censo da Constituição, e quanto aos analfabetos o direito de votar, ao menos enquanto a sociedade, por sua parte, não tiver cumprido o dever fundamental de pôr a instrução ao alcance de todo o mundo", onde está evidente uma alusão a Stuart Mill. Para o deputado, o projeto em discussão era "o banimento do povo da esfera de seus direitos", era "o exílio político da maioria dos cidadãos" (p. 710).

Os ataques mais duros ao projeto em questão partem de quatro tribunos de renome: Silveira Martins, Saldanha Marinho, José Bonifácio, o Moço, e Joaquim Nabuco. A começar por José Bonifácio, o Moço, no mesmo dia (10/2/1879) em que o gabinete Sinimbu perde dois de seus ministros:

As restrições pretendidas, elevando o censo arbitrariamente e excluindo os analfabetos, combinadas entre si, têm um vasto alcance, reduzem o eleitorado a muito menos do que seria conveniente e excluem do direito de voto uma enorme e reconhecida massa de cidadãos brasileiros, até hoje no gozo desse direito. É grave a questão; é a constituinte sem liberdade. [...] O censo elevado pode significar na prática a hipocrisia da eleição indireta (BONIFÁCIO [O MOÇO], 1879a, p. 432).

Decorridos cerca de dois meses da entrada projeto na Câmara, Saldanha Marinho (1879, p. 683-684) coloca em dúvida a natureza liberal do projeto Sinimbu: "A constituinte não pode alterar a significação das palavras", diz ele. E pergunta:

Ora, tirem-se os que não têm renda líquida, tirem-se os que não sabem ler, a que fica reduzido o direito de votar? É isto liberal? Os conservadores não o teriam feito melhor. Talvez mesmo nem aceitem tão avultado presente (MARINHO, 1879, p. 687). 
E questiona também a exclusão dos estrangeiros naturalizados e dos acatólicos, questão que levara à demissão dos ministros Silveira Martins e Barão de Vila Bela.

José Bonifácio, o Moço, (1879b) volta a atacar, dizendo que o Partido Liberal estava enrolando a bandeira "hasteada no Senado pelo censo baixo e pelo voto generalizado" (p. 748) e erguendo em seu lugar "o estandarte do privilégio no posto mais elevado onde devera erguer o da igualdade (Muito bem)" (p. 748). O projeto em discussão é, para ele, a negação do governo parlamentar, o suicídio moral de um partido; "Não é a bandeira da reforma, é a reforma da bandeira [liberal] (Apoiados)" (p. 748). A representação pretendida não passa, segundo ele, de um simulacro odioso. E desafia: "Dezenove partes da população sem voz no governo do Império, senhoreadas pelo resto... é um assombro! (Apoiados)" (p. 752).

Para José Bonifácio (1879b, p. 760), pelo censo e pela exclusão dos analfabetos, o projeto do governo "finge mandatários sem mandato", "constituindo uma fração mínima da população senhora absoluta de todos os habitantes do Império". E, respondendo à pergunta: “Qual o direto dos mandantes excluídos?”, diz: "Só lhes resta opor força à força".

Joaquim Nabuco (1879a, p. 770), favorável, como alguns outros deputados, ao voto universal, para ele "o grande ímã da democracia", limita-se aqui a condenar o aumento do censo: "Senhores, nós queremos o censo da Constituição, nós não viemos aqui pedir o sufrágio universal". De forma irônica, dirige-se àqueles que não sabiam ou não queriam fazer o cálculo de quantos resultariam excluídos do voto com a pretendida reforma: "A minha aritmética nesse ponto não falha; [...] porque, segundo a opinião do Sr. Stuart Mill, que prevalece nesta casa, não são só os analfabetos que não devem votar, são também os que não conhecem os princípios da aritmética" (NABUCO, 1879a, p. 763-769). Por fim, em outra fala, ao enfatizar a relação estreita que deveria haver entre eleição direta e instrução pública, proclama: "[...] no orçamento tudo avulta, menos a instrução pública" (NABUCO, 1879b, p. 201-206).

Defendendo o governo e desafiando os opositores, Inácio Martins (1879, p. 362) invoca Stuart Mill como parâmetro do liberalismo: "Os nobres deputados não quererão por certo ser mais liberais do que Stuart Mill”. E justifica: “[...] ele é tão liberal como os nobres deputados, exige para o exercício do voto a condição de saber ler e escrever, e além disso exigia mais o que Laboulaye dizia ser uma excentricidade inglesa: o saber fazer a conta de três (Riso)" (p. 362).

Para Martim Francisco (1879a, p. 402), irmão do já citado José Bonifácio, o Moço, "esta exclusão dos analfabetos nada tem de odiosa". Entende que é possível alfabetizar-se em 60 a 70 dias. E justifica: "Na província que represento, há meses atrás, dois professores que ensinavam a ler e escrever pelo método João de Deus, prepararam cada um vinte e tantos alunos, que levaram ao ins- 
petor da instrução pública" (p. 402). Em sua opinião, não se tratava de uma lei antiliberal, uma vez que concorria "para aquilo que há de mais essencial para os povos - a instrução primária". Para ele, "[...] o povo não tem o direito de ser ignorante" (p. 403). A certa altura do discurso, Galdino das Neves objeta: "Isto tudo é muito bom, mas não há escolas" (p. 403).

Em 28 de maio de 1879, Cansanção de Sinimbu (1879b, p. 425-426) sai em defesa do projeto, queixando-se de que o deputado por São Paulo (José Bonifácio, o Moço) o tenha condenado tão acremente ao considerá-lo "uma máquina de eliminações". Para o presidente do Conselho, a condição de saber ler e escrever "é o menos que se pode exigir como sinal de capacidade daquele que tem de concorrer diretamente para a escolha dos representantes da Nação (Muitos apoiados)" (p. 426).

No mesmo dia da fala de Sinimbu, José Bonifácio, o Moço, (1879c, p. 432) desafia: "Qual é, portanto, a vitória com que nos acenam? A vitória do censo sem máximo possível?! A vitória da exclusão dos analfabetos em um país como o nosso?! [...]". E ainda: "[...] não é a vitória da bandeira liberal que se festeja com a exclusão das massas" (p. 432). E numa referência ao autor inglês, questiona o próprio entendimento que os colegas deputados tinham da "quantidade certa" de conhecimento exigido por Stuart Mill, "tão citado nesta matéria" (p. 433).

José Bonifácio prossegue dizendo que as condições no Brasil não eram as dos países dos autores citados na Câmara, aí incluída com certeza a Inglaterra de Stuart Mill:

A opinião dos escritores, citados nesta casa para sustentar a famosa exclusão [dos analfabetos], não tem o valor que se lhe empresta; porque parte do ensino obrigatório e gratuito e assenta todo o seu raciocínio na generalidade ou facilidade da instrução primária. No Brasil não raciocinariam do mesmo modo. [...] E neste Império, sem mestres e sem discípulos, quando as estatísticas falam tão alto, vós fechais para o povo a grande escola do voto (BONIFÁCIO [O MOÇO], 1879c, p. 433, 438, grifo meu).

Em síntese, num Império sem escolas, o que se queria era fechar para o povo a única escola possível: a escola do voto, fechamento este que a República iria manter por mais de um século, até quase o final do século XX (1985), quando foi facultado o voto do analfabeto.

As palavras do Ministro da Justiça, o Sr. Lafayette Rodrigues Pereira (1879, p. 460), mostram bem como o analfabetismo estava se tornando um 
estigma: "Mas, admita-se, senhores, que oito décimos da população do império se compõem de analfabetos, eu pergunto-vos: - a ignorância, a cegueira, porque se torna vasta e numerosa, porque se generaliza, adquire o direito de governar? (Apoiados)". E o Ministro sentencia: "Se há no Império oito décimos de analfabetos, eu vos direi, esses oito décimos dever ser governados pelos dois décimos que sabem ler e escrever" (p. 460). Ao que Galdino das Neves responde: "É uma tirania..." (p. 460). Mas, para o ministro, o grupo dos que se opunham ao projeto não representava mais do que "o mau humor do partido" (p. 461).

Caído o governo Sinimbu, entra o governo Saraiva, com novo projeto de reforma eleitoral. Vários elementos contribuem para ampliar e reforçar as fileiras em torno do novo projeto: 1. um projeto de reforma por lei ordinária; 2. o prestígio do Conselheiro Saraiva no partido; 3. a ausência de José Bonifácio, agora no Senado; 4. a manutenção do censo em duzentos mil réis; 5. a incorporação, pelo governo, das alterações propostas pela comissão designada para emitir parecer; 6. a admissão dos não católicos, dos nacionalizados, dos ingênuos e dos libertos ao voto; e 7. a sutileza de reduzir a exclusão explícita dos analfabetos do direito de voto a uma questão meramente técnica - de assinatura e de fornecimento de recibo do diploma eleitoral.

Mas há dois fatos a ressaltar nesta parte. Em primeiro lugar, o novo projeto, se, de um lado, mantém o censo em 200 mil réis, de outro, detalha e endurece sobremaneira os mecanismos de comprovação deste. É o que observa o deputado Freitas Coutinho (1880, p. 15), por exemplo: "O ponto central do projeto consiste incontestavelmente na prova. [...] Entretanto, a prova do projeto não é acessível a todos [...] O projeto iludiu a muita gente". Em segundo lugar, na tramitação do projeto é restabelecida a exclusão explícita dos analfabetos, o que o projeto original não previa, como reconhecera o próprio Saraiva:

Mas o que faz o projeto? O projeto, sem exigir, como única, esta prova [de saber ler e escrever], exige-a como prova complementar para a regularidade da eleição. [...] Pelo projeto o indivíduo que não sabe ler nem escrever pode contudo ser qualificado como eleitor, mas não vota, se não aprende a assinar o seu voto e a escrever estas palavras - recebi o meu diploma. Não sabendo isto, não votará enquanto não o aprender (SARAIVA, 1880b, p. 92).

Em relação ao projeto Saraiva, os ventos foram mais favoráveis, a ponto de o deputado Lourenço de Albuquerque (1880, p. 322), defensor da exclusão dos analfabetos, ironizar aqueles que, no projeto anterior, haviam defendido o 
direito de voto dos analfabetos: "Onde estão, Sr. Presidente, os eloqüentes e fervorosos advogados dos analfabetos? Mudaram-se os tempos, e emudeceram esses rouxinóis da democracia! (Apoiados)".

Em síntese, a Lei manteve o censo, mas endurecendo os mecanismos de comprovação, e introduziu uma nova exclusão - a dos analfabetos.

\section{Sobre o estado da instrução pública no momento da reforma eleitoral}

Em aparte ao deputado Martim Francisco (1879a), que entendia que o povo não tinha direito a ser ignorante, o deputado Galdino das Neves manifestou-se de forma contundente: "Isto é muito bom, mas não há escolas" (p. 403). A questão é a seguinte: $\mathrm{O}$ que se sabe hoje sobre a cobertura escolar no período da reforma eleitoral de que se vem tratando neste texto?

O fato é que, decorridos apenas oito anos desde a Lei Saraiva (1881), precisamente no ano da proclamação da República, José Ricardo Pires de Almeida (1989), em sua História da instrução pública no Brasil (1500-1889), sintetizava, em tom nada animador, tanto as ideias subjacentes, de liberdade de ensino e de laissez-faire, quanto o alcance e os limites da reforma da educação operada precisamente pelo Conselheiro Carlos Leôncio de Carvalho, Ministro e Secretario de Estado dos Negócios do Império, no Governo presidido pelo Visconde de Sinimbu:

Em conformidade com estas ideias, apareceu o decreto de 19 de abril de 1879, reformando o ensino primário e secundário no município do Rio de Janeiro e o ensino superior no Império que declarava, pelo seu artigo $1^{\circ}$., estas diversas categorias de ensino inteiramente livres, salva a inspeção da autoridade sobre moralidade e higiene. O artigo tornava a instrução obrigatória para crianças de ambos os sexos, abaixo de catorze anos. Entretanto, esta medida atingia apenas os meninos situados em um raio de um quilômetro e meio em torno de uma escola pública e as meninas dentro de um raio de um quilômetro (ALMEIDA, 1989, p. 185).

Isto significa que a falta de recursos para a instrução pública denunciada por Joaquim Nabuco, como se disse acima, colocava uma dificuldade prática à obrigatoriedade escolar no Império, inclusive no município da Corte: faltavam 
escolas. Com efeito, o referido Decreto $\mathrm{n}^{\circ} 7.247$, de 1879, admitia isso expressamente, pelo que liberava de antemão de qualquer obrigatoriedade de frequência à escola "os que residirem a distância maior, da escola pública ou subsidiada mais próxima, de um e meio quilômetro para os meninos, e de um quilômetro para as meninas" (BRASIL, 1879, art. $2^{\circ}$ ). Se isto acontecia no município da Corte, pode-se facilmente imaginar em que nível andava, pelas diferentes províncias do Império, o provimento de escolas.

Por sua vez, é sombrio o quadro que Primitivo Moacyr desenha do estado da instrução pública no Império. Se, como diz o autor, na abertura da Assembleia Constituinte Legislativa, o Imperador Dom Pedro I afirmara haver promovido a instrução pública tanto quanto era possível, recomendando consideração para o assunto, não foi isto que se viu nos anos que se seguiram:

Na abertura da Assembleia Geral Legislativa, 1826, a primeira após a promulgação da Carta Constitucional de 1824, não voltou o Imperador a pedir para o ensino público a "suma consideração" de três anos atrás. Durante o período da Regência e das duas primeiras décadas da maioridade, o mesmo silêncio sobre a instrução, apesar dos vivos debates parlamentares de 1846 e 1847, e das queixas dos ministros do Império, em seus relatórios, sobre a deficiência de prédios escolares, de método e, sobretudo, da miséria em que se debatiam os mestres. Alguns insistiam pela criação de universidades (MOACYR, 1938, p. 662 , ortografia atualizada).

Somente em 1867 iríamos ter, pela primeira vez, as seguintes breves palavras sobre a instrução pública: "Promover a colonização deve ser objeto de vossa particular solicitude. De não menos desvelo se torna digna a instrução pública" (MOACYR, 1938, p. 662). Desse ano em diante, só se encontrariam, uma que outra vez, "algumas apressadas linhas sobre o desleixado ensino público" (p. 662), como na fala de 1868, em que o Imperador sustentava que o desenvolvimento da educação e instrução pública precisava ser um dos principais objetivos do ministério. Da mesma forma, nada de espetacular sobre a instrução pública nas falas do trono que se sucederam até 1889, "ano crepuscular do Império". Uma exceção teria sido o período de 1850-1858, em que se destacou a ação do ministro Couto Ferraz, com uma série de iniciativas, entre as quais, a reforma do ensino primário e secundário no Município da Corte (p. 667).

Mas a questão estava longe de se reduzir a uma simples falta de escolas. Como observa Vanilda Paiva (2003, p. 83), havia ali principalmente "um pro- 
blema teórico, discutido pelas elites": combatia-se a intervenção do estado, seja em nome do pátrio poder e do princípio do laisser faire, seja para entregar o ensino à direção exclusiva da Igreja, como pretendiam os "católicos retrógrados".

A pesquisa historiográfica recente no campo da educação tem questionado a matriz azevediana que teria apresentado o período pós-pombalino como um grande vazio (CARVALHO, 2005, p. 46-47). Vão nessa direção também as palavras de Faria Filho (2003):

A historiografia consagrada sempre concebe a educação primária do século XIX confinada entre a desastrada política pombalina e o florescimento da educação na era republicana. Tempo de passagem, o período imperial não poucas vezes é entendido, também, como a nossa idade das trevas ou como um mundo onde, estranhamente, as ideias estão, continuamente, fora de lugar (FARIA FILHO, 2003, p. 135).

Segundo Faria Filho (2003, p. 146-147, 149, nota 1), o exemplo clássico dessa abordagem é a obra A cultura brasileira de Fernando de Azevedo. Ao contrário disso, segundo o autor citado, no Brasil, a educação escolar teria assumido progressivamente, ao longo do século XIX, "as características de uma luta do governo do estado contra o governo da casa" (p. 146), no sentido de afastar a escola do recinto doméstico. No entanto, há que destacar que, segundo o autor citado, se as críticas sobre o estado precário da instrução pública vinham se acumulando desde a primeira metade do século XIX, o Brasil teria tido que aguardar até meados da primeira década republicana "para ver entrarem em funcionamento as primeiras construções públicas” (p. 147) (grupos escolares), a começar por São Paulo.

Seguindo essa linha de raciocínio, parece que não seria fora de propósito questionar a pertinência de se estender para todo o Império a conclusão a que chega M. L. Marcílio (2005) em seu livro História da escola em São Paulo e no Brasil, qual seja, que os anos 1870 marcariam o início do que ela chama "Século da Escola". A autora diz que "o Império foi promovendo um processo lento, muito lento, mas sustentado de difusão das aulas públicas das grandes cidades até os mais remotos e isolados povoados" (p. 88). Diz também que "Esse processo foi morosamente montado no Império e foi essencial para o 'Século da Escola' [...] que começa com os anos de 1870 e se firma com a República” (p. 89). Se isto é verdade para o conjunto do país, como explicar que, do recenseamento de 1872 para aquele de 1890 , a taxa nacional de analfabetismo se tenha mantido no mesmo nível, acima de $80 \%$ para a população de 5 anos ou mais $(82,3$ e 82,6\%, 
respectivamente), como se tem mostrado já de longa data? E note-se que isto vale também para o Estado de São Paulo ( 81,2 e 83,2\%, respectivamente em 1872 e 1890) (FERRARI[O], 1985, p. 43, Tabela 6).

Não se trataria nesse período de mudanças que ficaram muito no plano do discurso, como se intui do texto acima citado de Faria Filho (2003) e como sugere M. C. G. Machado (2005, p. 91-92) quando diz que o que se destaca nas últimas duas décadas do Império é "a emergência de debates em torno da necessidade de criação da escola para as classes populares sob a tutela do Estado"? Confirma esse ponto de vista o simples fato de que, dos sete projetos de reforma registrados por Primitivo Moacyr (1937) no curto período de 1870 a 1886 e listados pela autora, nenhum deles tenha sido implementado. Nem o de Leôncio de Carvalho, de 1879.

Não se tem, aqui, a pretensão de haver esgotado o assunto, muito menos de haver respondido satisfatoriamente à questão levantada sobre o nível de provimento de escolas no segundo Reinado em geral e no período da reforma eleitoral (1878-1881) em particular. Parece, apenas, que as duas ou três últimas décadas do Império continuam constituindo-se num desafio para a pesquisa em história da educação no Brasil. Por enquanto, parece que não estava de todo desprovido de razão o Deputado Galdino das Neves, quando, como se viu anteriormente (FRACISCO, 1879a, p. 403), dizia: "Isto tudo é muito bom, mas não há escolas".

\section{Sobre as mulheres votarem}

Por que os liberais brasileiros, que não só abraçaram, mas até radicalizaram as exclusões defendidas por Stuart Mill (dos homens de baixa renda e dos analfabetos), ignoraram quase que por completo a tese do autor favorável à extensão do voto às mulheres? Disse "quase por completo", porque a leitura dos Anais da Câmara acusa um debate interessante sobre a questão.

Com efeito, em aparte ao discurso do deputado Martim Francisco (1879b, p. 598-599), o Deputado Zama desencadeou debate sobre voto e instrução das mulheres. Dizia o Sr. Zama (p. 598) já haver-se entendido com o seu colega de deputação, então Ministro do Império (Leôncio de Carvalho), tendo obtido em particular uma solução a respeito da questão do voto ativo e passivo, que, em sua opinião, deveria ser concedido também às mulheres em matéria política. Palavras estas, que foram cortadas por um "Deus nos livre disso!" (p. 598) do deputado Freitas Coutinho. Retomando a palavra, Martin Francisco (1879b), 
ao mesmo tempo em que condena "o cerceamento injustificável em relação ao público interesse de metade da humanidade, não menos inteligente, não menos apta para o desempenho dos deveres políticos do que a parte masculina" (p. 598599), parece remeter para as calendas gregas a participação política da mulher ao dizer: "é preciso preparar a mulher pela educação para o desempenho dos seus direitos políticos (apoiados), dando-lhe aptidão e condições práticas para que ela possa realizar estes direitos" (p. 599). Fica subentendido que, para o deputado, a mulher não tinha ainda tal aptidão e condições (p. 598-599).

A partir daí o assunto se torna hilariante, com vários apartes, após o que Martim Francisco (1879b) retoma seu discurso, dizendo ter opiniões firmadas "nas recomendáveis obras de Stuart Mill, O Sistema Representativo e A servidão da Mulher" (p. 599). Rui Barbosa, por sua vez, intervém no debate tentando desviar a discussão: "Mas enquanto não vem o voto das mulheres venha a elegibilidade dos acatólicos" (p. 599). Retornando ao tema, Martim Francisco ressalva que, naquele momento, a sua aspiração não era o acesso das mulheres ao voto, "mas tornar possível o estudo da medicina às mulheres" (p. 598-599).

Rodolfo Dantas (1879, p. 119), por sua vez, situa as mulheres entre os incapazes, ao lado dos escravos e dos menores de 21 anos.

O fato é que, apesar de Stuart Mill ser favorável à extensão do voto à mulher e de os deputados liberais brasileiros terem plena consciência disso, a mulher brasileira teve que aguardar por mais de meio século (até 1932) para ter acesso ao voto. Aliás, as próprias mulheres, em sua maioria, não se colocavam ainda com clareza a questão da participação politica. Nem podiam colocar-se, uma vez que,

Excluídas de uma efetiva participação na sociedade, da possibilidade de ocuparem cargos públicos, de assegurarem dignamente sua própria sobrevivência e até mesmo impedidas do acesso à educação superior, as mulheres no século XIX ficavam trancadas, fechadas dentro de casas ou sobrados, mocambos e senzalas, construídos por pais, maridos, senhores (TELLES, 2002, p. 408).

Uma década e pouco antes da reforma eleitoral, o naturalista L. Agassiz e sua esposa E. C. Agassiz (2000, p. 435) haviam feito uma avaliação nada otimista em relação à educação da mulher no Brasil: "Em geral, no Brasil, pouco se cuida da educação da mulher; o nível da instrução dada nas escolas femininas é pouquíssimo elevado; [...] a educação das jovens é pouco cuidada e o tom geral da sociedade disso se ressente". 
Mais para o final de século XIX, as coisas começavam mudar no que respeita à instrução pública e ao acesso ao mercado de trabalho. Como observa June H. Hanner (2003, p. 115), as primeiras defensoras dos direitos da mulher no Brasil viam na educação uma "chave para a emancipação feminina e a melhoria de status". No tempo da reforma eleitoral de que se vem tratando, elas lutavam inclusive pelo acesso ao ensino superior, com atenção voltada para o direito e a medicina, o que obtiveram na lei de reforma educacional de Leôncio de Carvalho em 1879. A questão do voto não tardaria a se colocar: "Muitas finalmente advogavam o direito ao voto, uma demanda que chocava ou surpreendia a muitos homens mas que foi debatida, e negada, no congresso constituinte de 1891" (HANNER, 2003, p. 115).

\section{Consequências da Lei Saraiva}

Não é fácil avaliar as consequências da Lei Saraiva. Da mesma forma, avaliar o que se podia esperar do tipo de liberalismo que vingara no Brasil Império, latifundiário, de economia essencialmente agrária e ainda teimosamente escravocrata ao tempo da reforma eleitoral de introdução do voto direto.

Quanto ao liberalismo doméstico, os próprios parlamentares liberais tinham consciência da curta distância que os separava, então, dos conservadores. São significativas as palavras proferidas por Martinho A. S. Campos em seu discurso de posse como sucessor de J. A. Saraiva na presidência do Conselho de Ministros: "[...] são duas coisas parecidas - um liberal e um conservador - e podia mesmo acrescentar-se um republicano, porque têm todos os mesmos ares de família" (COSTA, 2007, p. 161). Um pouco como na Colômbia de Cien Años de Soledad, onde se ouvia dizer que "La única diferencia actual entre liberales y conservadores, es que los liberales van a misa de cinco y los conservadores van a misa de ocho" (MÁRQUEZ, 2007, p. 278). Coisa que o deputado Zama (1880), que se tinha por liberal avançado e buscava em Stuart Mill suporte para a sua tese de que a instrução primária haveria de ser a única estrada para o voto universal, expressou de forma escultural nessas palavras: "Quero, entretanto, que se vá pouco a pouco preparando a estrada pela qual, com o correr dos tempos, os nossos vindouros lá possam chegar sem sobressaltos. Essa estrada é, e há de ser a instrução primaria" (ZAMA, 1880, p. 425, grifos meus).

No entanto, por que é que até esse "pouco a pouco" do deputado Zama enfrentou tanta dificuldade? Primeiro, porque, ao contrário do que proclamavam 
os seus autores, a Lei Saraiva (1881), longe de ampliar a participação política no país, reduziu-a drasticamente de mais de 1 milhão de votantes (em primeiro turno) antes da reforma, o que equivalia a aproximadamente $13 \%$ da população livre adulta, para pouco mais de 100 mil eleitores após a reforma, algo como $0,8 \%$ da referida população. Só 75 anos mais tarde, em 1945, o país voltaria a atingir e superar levemente $(13,4 \%)$ o percentual de comparecimento às urnas do final da década de 1870 (13\%) (CARVALHO, 2004, p. 38-40).

Segundo, porque a história posterior à Lei Saraiva, com o coronelismo político, os currais e os mapas eleitorais, mostra que nem o censo nem a exclusão dos analfabetos - estes frequentemente associados, nos debates parlamentares, aos bijus, navalhistas, capoeiras e cacetistas - conseguiram moralizar o processo eleitoral.

Terceiro, porque o Brasil chegou ao ano 2000 com duas vezes mais analfabetos do que tinha 120 anos antes, ao tempo da Lei Saraiva. O que confirma que a exclusão dos analfabetos do direito de voto, ao contrário do apregoado, não forçou o povo a procurar escola, muito menos o governo a ampliar seu número e a universalizar o ensino.

Quarto, porque, enquanto em 1884, logo após a Lei Saraiva, a República Argentina estabelecia o ensino obrigatório pela Lei $\mathrm{n}^{\circ} 1.420$ (ARGENTINA, 1984), os brasileiros e as brasileiras teriam que aguardar até 1934 para ver assegurada na Constituição a obrigatoriedade escolar.

Por isso tudo, talvez seja pouco dizer que a Lei Saraiva foi um "tropeço" (CARVALHO, 2004, p. 38). Parece mais apropriado dizer que ela foi um gigantesco retrocesso em termos de participação política e que, quanto à educação, certamente não representou avanço.

Acredita-se que dois conceitos freireanos podem iluminar o caso. Em que pesem alguns avanços (o voto direto e sua extensão aos acatólicos, naturalizados, ingênuos e libertos), a reforma eleitoral em questão, pelos seus elementos de exclusão (de negação do voto às pessoas de baixa renda, aos analfabetos e às mulheres), parece aproximar-se muito do que se poderia chamar de ação preventiva, de contenção da participação popular, no sentido de manter a situação-limite favorável e de afastar a possibilidade de qualquer inédito viável, como o voto universal (FREIRE, 1979, p. 105-111).

Por fim, em contraposição à declaração de voto do deputado Zama (1880, p. 428-433), de que votaria pelo projeto, por entender que este haveria de marcar, na história do país, uma época gloriosa tanto para o nome de J. A. Saraiva quanto para o Partido Liberal, acompanha-se a avaliação do deputado Beltrão, o qual lhe retruca secamente: "Não por este projeto!” (p. 433). 


\section{REFERÊNCIAS}

ABREU, F. de. [Discurso]. In: CÂMARA DOS DEPUTADOS. Annaes da Câmara dos Deputados, sessão de 30 de janeiro de 1879. Rio de Janeiro: Typographia Nacional, 1879. p. 317-322. Disponível em: < http://imagem.camara.gov.br/dc_20b.asp?selCodC olecaoCsv=A\&Datain=30/1/1879>. Acesso em: 17/1/2007.

AGASSIZ, L.; AGASSIZ, E. C. Viagem ao Brasil 1865-1866. Tradução e notas de Edgar Süssekind de Mendonça. Brasília, DF: Senado Federal, Conselho Editorial, 2000.

ALBUQUERQUE, L. de. [Discurso]. In: CÂMARA DOS DEPUTADOS. Annaes da Câmara dos Deputados, sessão de 19 de junho de 1880. Rio de Janeiro: Typographia Nacional, 1980. p. 320-322. Disponível em: <http://imagem.camara.gov.br/dc_20b.asp ?selCodColecaoCsv=A\&Datain=19/6/1880>. Acesso em: 9/1/2007.

ALMEIDA, J. R. P. de. História da instrução pública no Brasil (1500-1889): história e legislação. Tradução de Antonio Chizzotti. São Paulo: EDUC; Brasília, DF: INEP/ MEC, 1989.

ARGENTINA. Debate parlamentário: Ley 1.420, 1883-1884. Estudio preliminar, selección y notas Gregorio Weinberg. Buenos Aires: Centro Editor de América Latina, 1984.

BADINTER, E. (Org.). Palavras de homens (1790-1793). Rio de Janeiro: Nova Fronteira, 1991.

BARBOSA, R. [Discurso]. In: CÂMARA DOS DEPUTADOS. Annaes da Câmara dos Deputados, sessão de 21 de junho de 1880. Rio de Janeiro: Typographia Nacional, 1880. p. 348-369. Disponível em: <http://imagem.camara.gov.br/dc_20b.asp?selCodColecao Csv=A\&Datain=21/6/1880>. Acesso em: 9/1/2007.

BONIFÁCIO [O MOÇO], J. [Discurso]. In: CÂMARA DOS DEPUTADOS. Annaes da Câmara dos Deputados, sessão de 10 de fevereiro de 1879. Rio de Janeiro: Typographia Nacional, 1879a.p. 430-432. Disponível em: $<$ http://imagem.camara.gov.br/dc_20b.asp ?selCodColecaoCsv=A\&Datain=10/2/1879>. Acesso em: 17/1/2007.

. [Discurso]. In: CÂMARA DOS DEPUTADOS. Annaes da Câmara dos Deputados, sessão de 28 de abril de 1879. Rio de Janeiro: Typographia Nacional, 1879b. p. 747-753, 755-761. Disponível em: <http://imagem.camara.gov.br/dc_20b.asp?selCodC olecaoCsv=A\&Datain=28/4/1879>. Acesso em: 29/6/2007.

. [Discurso]. In: CÂMARA DOS DEPUTADOS. Annaes da Câmara dos Deputados, sessão de 28 de maio de 1879. Rio de Janeiro: Typographia Nacional, 1879c. p. 428, 438. Disponível em: <http://imagem.camara.gov.br/dc_20b.asp?selCodColecaoC Sv=A\&Datain=28/5/1879>. Acesso em: 29/6/2007.

BRASIL. Constituição (1824). Constituição Política do Império do Brazil. Rio de Janeiro: Alvarás e Cartas Imperiaes, 1824.

. Decreto $n^{\circ} 7.247$, de 19 de abril de 1879 . Reforma o ensino primario e secundario no municipio da Côrte e o superior em todo o Imperio. Coleção de Leis do Império 
do Brasil, Rio de Janeiro, 1879. Disponível em: < http:/www2.camara.leg.br/legin/fed/ decret/1824-1899/decreto-7247-19-abril-1879-547933-publicacaooriginal-62862-pe. html>. Acesso em: 13/7/2013.

. Decreto n ${ }^{\circ} 3.029$, de 9 de janeiro de 1881. Lei Saraiva, Lei do Censo. Reforma a legislação eleitoral. Coleção de Leis do Império do Brasil, Rio de Janeiro, 1881.

BURKE, P. Sociologia e história. 2. ed. Porto: Afrontamento, 1980.

CARVAlHO, J. M. de. Cidadania no Brasil: o longo caminho. 5. ed. Rio de Janeiro: Civilização Brasileira, 2004.

CARVALHO, M. M. C. História e historiografia da escola pública no Brasil: algumas considerações em torno de um programa de investigação. In: LOMBARDI, J. C.; SAVIANI, D.; NASCIMENTO, M. I. M. (Orgs.). A escola pública no Brasil - história e historiografia. Campinas: Autores Associados, 2005. p. 33-64. (Coleção Memória da Educação).

CELSO, A. [Discurso]. In: CÂMARA DOS DEPUTADOS. Annaes da Câmara dos Deputados, sessão de 24 de janeiro de 1879. Rio de Janeiro: Typographia Nacional, 1879. p. 111-123. Disponível em: <http://imagem.camara.gov.br/dc_20b.asp?selCodC olecaoCsv=A\&Datain=24/1/1879>. Acesso em: 17/1/2007.

CONDORCET, [J. A. N. de C.] Marquês de. Sobre a admissão das mulheres ao direito de cidadania. In: BADINTER, E. (Org.). Palavras de homens (1790-1793). Rio de Janeiro: Nova Fronteira, 1991. p. 43-52.

COSTA, E. V. da. Da monarquia à república. Momentos decisivos. 8. ed. São Paulo: UNESP, 2007.

COUTINHO, F. [Discurso]. In: CÂMARA DOS DEPUTADOS. Annaes da Câmara dos Deputados, sessão de 3 de junho de 1880. Rio de Janeiro: Typographia Nacional, 1880. p. 14-16. Disponível em: <http://imagem.camara.gov.br/dc_20b.asp?selCodColecaoCs $\mathrm{v}=$ A\&Datain=3/6/1880>. Acesso em: 9/1/2007.

DANTAS, R. [Discurso]. In: CÂMARA DOS DEPUTADOS. Annaes da Câmara dos Deputados, sessão de 17 de junho de 1879. Rio de Janeiro: Typographia Nacional, 1879. p. 116-123. Disponível em: <http://imagem.camara.gov.br/dc_20b.asp?selCodColecao Csv=A\&Datain=17/6/1879>. Acesso em: 29/6/2007.

FALA DO TRONO. [Discurso]. In: CÂMARA DOS DEPUTADOS. Annaes da Câmara dos Deputados, sessão de 15 de dezembro de 1878. Rio de Janeiro: Typographia Nacional, 1878. p. 92-93. Disponível em: <http://imagem.camara.gov.br/dc_20b.asp?selCodCole caoCsv=A\&Datain=15/12/1878>. Acesso em: 19/8/2007.

FARIA FILHO, L. M. de. Instrução elementar no século XIX. In: LOPES, Eliane Marta Teixeira; FARIA FILHO, Luciano Mendes de; VEIGA, Cúnhia Greive (Orgs.). 500 anos de educação no Brasil. 3. ed. Belo Horizonte: Autêntica, 2003. p. 135-150.

FERRARI[O], A. R. Analfabetismo no Brasil: tendência secular e avanços recentes. Resultados preliminares. Cadernos de Pesquisa, São Paulo, n. 52, p. 39-49, fev. 1985. 
FERRARO, A. R. A negação do direito de voto aos analfabetos na Lei Saraiva (1881): uma exclusão de classe? Revista de Educação Ciência e Cultura, Canoas, v. 13, p. 13-22, 2008.

. A construção social do analfabetismo como questão nacional: 1878-1881. In: . História inacabada do analfabetismo no Brasil. São Paulo: Cortez, 2009. p.

53-84.

; LEÃO, M. de. Lei Saraiva (1881): dos argumentos invocados pelos liberais para a exclusão dos analfabetos do direito de voto. Educação Unisinos, São Leopoldo, v. 16, p. 241-250, 2012.

FRANCISCO, M. [Discurso]. In: CÂMARA DOS DEPUTADOS. Annaes da Câmara dos Deputados, sessão de 19 de abril de 1879. Rio de Janeiro: Typographia Nacional, 1879b. p. 598-599. Disponível em: <http://imagem.camara.gov.br/dc_20b.asp?selCod ColecaoCsv=A\&Datain=19/4/1879>. Acesso em: 29/10/2007.

. [Discurso]. In: CÂMARA DOS DEPUTADOS. Annaes da Câmara dos Deputados, sessão de 27 de maio de 1879. Rio de Janeiro: Typographia Nacional, 1879a. p. 398-405. Disponível em: <http://imagem.camara.gov.br/dc_20b.asp?selCodColecaoCs $\mathrm{v}=$ A\&Datain=27/5/1879>. Acesso em: 1/7/2007.

FREIRE, P. Pedagogia do oprimido. 6. ed. Rio de Janeiro: Paz e Terra, 1979.

GROULT, B. Le féminisme au masculin. Paris: Grasset, 2010.

HAHNER, J. E. Emancipação do sexo feminino: a luta pelos direitos da mulher no Brasil. 1850-1940. Tradução de Eliane Lisboa. Florianópolis: Mulheres; Santa Cruz do Sul, 2003.

HOLANDA, S. B. de (Dir.). Do império à república. 2. ed. Rio de Janeiro; São Paulo: Difel, 1977. (Coleção História geral da civilização brasileira; tomo II - O Brasil monárquico; v. 5).

(Dir.). Reações e transações. 4. ed. São Paulo: Difel, 1982. (Coleção História

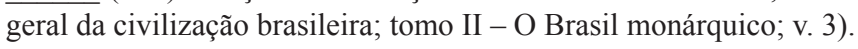

JAVARI, Barão de. Organizações e programas ministeriais. 2. ed. Rio de Janeiro: 1962.

LEÃO, M. de. A participação de Rui Barbosa na reforma eleitoral que excluiu os analfabetos do direito de voto no Brasil. 122 f. Dissertação (Mestrado em Educação) - Programa de Pós-Graduação em Educação, Faculdade de Educação, Universidade Federal do Rio Grande do Sul, Porto Alegre, 2013.

MACHADO, M. C. G. de. O decreto de Leôncio de Carvalho e os pareceres de Rui Barbosa em debate. A criação da escola para o povo no Brasil no século XIX. In: STEPHANOU, M.; BASTOS, M. H. C. (Orgs.). Histórias e memórias da educação no Brasil. Petrópolis: Vozes, 2005. p. 91-103. (V. II - Século XIX).

MARCÍliO, M. L. História da escola em São Paulo e no Brasil. São Paulo: Imprensa Oficial do Estado de São Paulo, Instituto Fernand Braudel, 2005.

MARINHO, S. [Discurso]. In: CÂMARA DOS DEPUTADOS. Annaes da Câmara dos Deputados, sessão de 23 de abril de 1879. Rio de Janeiro: Typographia Nacional, 1879. 
p. 680-693. Disponível em: <http://imagem.camara.gov.br/dc_20b.asp?selCodColecao Csv=A\&Datain=23/4/1879>. Acesso em: 1/1/2007.

MÁRQUEZ, G. G. Cien años de soledad. Edición conmemorativa. Espanha: Alfaguara, 2007.

MARTINS, I. [Discurso]. In: CÂMARA DOS DEPUTADOS. Annaes da Câmara dos Deputados, sessão de 23 de maio de 1879. Rio de Janeiro: Typographia Nacional, 1879. p. 359-362. Disponível em: <http://imagem.camara.gov.br/dc_20b.asp?selCodColecao Csv=A\&Datain=23/5/1879>. Acesso em: 1/7/2007.

MILL, J. S. Considerações sobre o governo representativo. Tradução de Manoel Inocêncio de Lacerda Santos Jr. Brasília, DF: UnB, 1981.

. Autobiografía. Prólogo y notas de Carlos Mellizo. Madrid: Alianza, 1986.

. Sobre a liberdade. Petrópolis: Vozes, 1991.

. El utilitarismo. Introducción, traducción y notas de Esperanza Guisán. 3. reimpr. Madrid: Alianza, 1997.

. On liberty and others essays. Introduction and notes by John Gray. Oxford: Oxford University, 2008.

. The subjection of women. In: . On liberty and others essays. Introduction and notes by John Gray. Oxford: Oxford University, 2008. p. 469-592.

MOACYR, Primitivo. A instrução e o Imperio. Subsídios para a Historia da Educação no Brasil: 1850-1888. v. 2. São Paulo: Nacional, 1937.

. A instrução e o Imperio. Subsídios para a Historia da Educação no Brasil. 18541889. v. 3. São Paulo: Nacional, 1938.

NABUCO, J. [Discurso]. In: CÂMARA DOS DEPUTADOS. Annaes da Câmara dos Deputados, sessão de 29 de abril de 1879. Rio de Janeiro: Typographia Nacional, 1879a. p. 763-773. Disponível em: <http://imagem.camara.gov.br/dc_20b.asp?selCodColecao Csv=A\&Datain=29/4/1879>. Acesso em: 1/4/2007.

. [Discurso]. In: CÂMARA DOS DEPUTADOS. Annaes da Câmara dos Deputados, sessão de 15 de maio de 1879. Rio de Janeiro: Typographia Nacional, 1879b. p. 199-208. Disponível em: <http://imagem.camara.gov.br/dc_20b.asp?selCodColecaoCs $\mathrm{v}=$ A\&Datain $=15 / 5 / 1879>$. Acesso em: 1/1/2007.

NYE, A. Teoria feminista e as filosofias do homem. Tradução Nathanael C. Caixeiro. Rio de Janeiro: Record; Rosa dos Tempos, 1995.

PAIVA, V. História da educação no Brasil: educação popular e educação de adultos. 6. ed. revista e ampliada. São Paulo: Loyola, 2003.

PEIXOTO, G. [Discurso]. In: CÂMARA DOS DEPUTADOS. Annaes da Câmara dos Deputados, sessão de 25 de abril de 1879. Rio de Janeiro: Typographia Nacional, 1879. p. 707-711. Disponível em: $<$ http://imagem.camara.gov.br/dc_20b.asp?selCodColecao Csv=A\&Datain=25/4/1879>. Acesso em: 1/7/2007. 
PEREIRA, L. R. [Discurso]. In: CÂMARA DOS DEPUTADOS. Annaes da Câmara dos Deputados, sessão de 29 de maio de 1879. Rio de Janeiro: Typographia Nacional, 1879. p. 453-461. Disponível em: <http://imagem.camara.gov.br/dc_20b.asp?selCodC olecaoCsv=A\&Datain=29/5/1879>. Acesso em: 29/6/2007.

POLETTI, Ronaldo (Org.). Constituições brasileiras: 1934. 2. ed. Brasília, DF: Senado Federal, CEE/MCT, ESAF/MF, 2001. (v. III).

ROMERO, S. Realidades e ilusões no Brasil: parlamentarismo e presidencialismo e outros ensaios. Seleção e coordenação de Hildon Rocha. Petrópolis: Vozes, 1979.

SARAIVA, J. A. [Discurso]. In: CÂMARA DOS DEPUTADOS. Annaes da Câmara dos Deputados, sessão de 22 de abril de 1880. Rio de Janeiro: Typographia Nacional, 1880a. p. 8-9. Disponível em: <http://imagem.camara.gov.br/dc_20b.asp?selCodColec aoCsv=A\&Datain=22/4/1880 $>$. Acesso em: 15/12/2008.

. [Discurso]. In: CÂMARA DOS DEPUTADOS. Annaes da Câmara dos Deputados, sessão de 7 de junho de 1880. Rio de Janeiro: Typographia Nacional, 1880b. p. 89-93. Disponível em: <http://imagem.camara.gov.br/dc_20b.asp?selCodColecaoCsv= A\&Datain=7/6/1880>. Acesso em: 9/1/2007.

SAVIANI, D. História da escola pública no Brasil: questões para pesquisa. In: LOMBARDI, José Claudinei; SAVIANI, Dermeval; NASCIMENTO, Maria Isabel Moura (Orgs.). História da escola pública no Brasil: questões para pesquisa. Campinas: Autores Associados; HISTEDBR, 2005. p. 1-29. (Coleção Memória da Educação).

SINIMBU, C. de. [Discurso]. In: CÂMARA DOS DEPUTADOS. Annaes da Câmara dos Deputados, sessão de 10 de fevereiro de 1879. Rio de Janeiro: Typographia Nacional, 1879a. p. 415. Disponível em: <http://imagem.camara.gov.br/dc_20b.asp?selCodColec aoCsv=A\&Datain=10/2/1879>. Acesso em: 17/1/2007.

SINIMBU, C. de. [Discurso]. In: CÂMARA DOS DEPUTADOS. Annaes da Câmara dos Deputados, sessão de 28 de maio de 1879. Rio de Janeiro: Typographia Nacional, 1879b. p. 422-428. Disponível em: <http://imagem.camara.gov.br/dc_20b.asp?selCod ColecaoCsv=A\&Datain=28/5/1879>. Acesso em: 29/6/2007.

TELLES, N. Escritoras, escritas, escrituras. In: DEL PRIORE, Mary (Org.); BASSANESI, Carla (Coord. de Textos). História das mulheres no Brasil. 6. ed. São Paulo: Contexto, 2002. p. 401-444.

ZAMA, C. [Discurso]. In: CÂMARA DOS DEPUTADOS. Annaes da Câmara dos Deputados, sessão de 23 de junho de 1880. Rio de Janeiro: Typographia Nacional, 1880. p. 420-433. Disponível em: <http://imagem.camara.gov.br/dc_20b.asp?selCodColecao Csv=A\&Datain=23/6/1880>. Acesso em: 9/1/2007.

Texto recebido em 06 de dezembro de 2012.

Texto aprovado em 24 de julho de 2013. 